\title{
TEORIAS DA ADMINISTRAÇÃO: UMA “EVOLUÇÃO” SEM COR?
}

\author{
THEORIES OF ADMINISTRATION: A "EVOLUTION" WITHOUT COLOR?
}

\author{
Elisângela de Jesus Furtado da Silva ${ }^{1}$, Laysse Fernanda Macêdo dos Santos ${ }^{1}$, \\ Felipe Mateus Assis Soares ${ }^{1}$
}

1 Universidade Federal de Minas Gerais, Faculdade de Ciências Econômicas, Brasil, elisangelafurtado23@gmail.com

\section{ARTICLE INFO}

Article history:

Received 2018-0704

Accepted 2019-02-01

Available online 2019-02-07
Palavras-chave: Teorias da administração. Raça. Etnia. Diversidade.

Keywords: Theories of administration. Breed. Ethnicity. Diversity.

RESUMO. As questões sociais estão presentes no interior das organizações e sendo essas consideradas formas organizativas da sociedade, questiona-se como as Teorias da Administração tratam questões de ordem social sob a ótica étnico racial, abordagem justificada em função da existência de estudos que demonstram aspectos da desigualdade existente no Brasil, além do antecedente de escravização, bem como sua implicação social na atualidade. A reflexão teórica evidenciou que até década de 80 as Teorias da Administração tiveram sua evolução pautada unicamente pelos fatores relacionados diretamente aos objetivos organizacionais, fato que tornou alheio qualquer outra questão e aí estão as sociais, de análise científica nessa área do saber. Com a ascensão e repercussão de estudos críticos, questões sociais passaram a ser debatidas no ambiente organizacional e tecnologias gerenciais foram criadas visando reformar os processos produtivos, porém a criação e adoção de práticas e técnicas voltadas à promoção das diferenças nas organizações não é suficiente para promover a profundidade demandada por questões sociais complexas como é caso do racismo proveniente da discriminação étnico racial, do sexismo, da homofobia e tantos outros, pois tratam-se de processos desenvolvidos sob um manto da negação de sua existência por centenas de anos no contexto brasileiro.

ABSTRACT. Social issues are present within organizations and these are considered organizational forms of society, it is questioned how the Theories of Administration address social issues from the racial ethnic viewpoint, an approach justified by the existence of studies that demonstrate aspects of inequality existing in Brazil, besides the antecedent of enslavement, as well as its social implication in the present time. Theoretical reflection evidenced that until the 80 s, theories of administration had their evolution guided only by factors directly related to organizational objectives, a fact that made it unrelated to any other question and there are the social, scientific analysis in this area of knowledge. With the rise and repercussion of critical studies, social issues began to be debated in the organizational environment and managerial technologies were created aiming to reform productive 
processes, but the creation and adoption of practices and techniques aimed at promoting differences in organizations is not enough to promote the depth demanded by complex social issues such as racism stemming from racial discrimination, sexism, homophobia and many others, since they are processes developed under a blanket denying their existence for hundreds of years in the Brazilian context.

\section{Introdução}

Os avanços tecnológicos observados a partir do século XIX impulsionaram fortemente o surgimento e crescimento das organizações modernas, voltadas à satisfação das necessidades humanas, conforme a crença de Smith (1996). As Teorias da Administração se desenvolveram no sentido do aperfeiçoamento da velocidade de produção, tamanho da empresa, aplicação eficiente de recursos, além da expansão do capital, dito de outra forma, houve ênfase nos processos, dada sua relação direta com os objetivos organizacionais sendo que aspectos que não apresentam ligação direta com esses fatores foram marginalizados. Ao analisar a Administração na perspectiva política, Caribé (2008) afirma que a importância crescente desse campo do saber está profundamente ligada ao sistema de produção vigente, condição que produz reflexos nas Teorias da Administração, aspecto esse pouco problematizado (CHRISTIANS, 2006).

Com o crescimento dos estudos organizacionais sob a ótica da cultura o elemento humano passa a ser central, porém percebido enquanto potencialidade econômica para as empresas, dada a crença de que conhecer a cultura daria subsídio para controlá-la (SILVA, et. al, 2017). Porém, de forma paralela houve o desenvolvimento de um intenso debate sobre processos opressores presentes na sociedade reproduzidos no interior das organizações, cenário ilustrado pelos estudos feministas voltados à desnaturalização das formas de opressão impostas às mulheres (CHRISTIANS, 2006). Assim, por vários anos, a evolução das tecnologias gerenciais por meio do desenvolvimento das Teorias da Administração, ocorreu de forma alheia às questões sociais como o sexismo, a segregação social e o racismo.

As questões sociais estão presentes no interior das organizações e sendo essas consideradas formas organizativas da sociedade (LAVALLE; CASTELLO; BICHIR, 2007), questiona-se como as Teorias da Administração abordam questões de ordem social sob a ótica étnico racial. É válido ressaltar que o debate étnico racial se refere a diversos grupos sociais como bem lembra Rosa (2012) citando os indígenas, asiáticos e judeus. A abordagem adotada no presente trabalho é justificada em função da existência de estudos que demonstram aspectos da desigualdade existente no Brasil, além do antecedente de escravização, bem como sua implicação social na atualidade (BERNARDINO, 2002; 
DOMINGUES, 2008; LIMA, 2010). Como forma de abordar a temática evidenciada, este ensaio tem como objetivo descrever as Teorias da Administração, problematizar o desenvolvimento nelas proposto bem como analisar as implicações sociais relacionadas à questão étnico racial.

\section{Fundamentação}

Para a compreensão da evolução das Teorias da Administração faz-se necessário conhecê-las em um sentido amplo, considerando o contexto em que surgiram e quem são os seus autores. Para tanto, a seguir está a descrição de forma sintética da Evolução das Teorias da Administração. Posteriormente, há um tópico que trata da "Gestão da Diversidade: Promoção das diferenças ou controle? O próximo tópico problematiza o desenvolvimento perseguido pelas organizações intitulado "Teorias da Administração: Desenvolvimento para quem? Por fim, apresentam-se as "Considerações Finais".

\subsection{Evolução das teorias da administração}

No final do século $X I X$ e começo do século $X X$, o mundo vivenciou uma grande transformação pautada pela Revolução Industrial. Surgiram novas preocupações voltadas à elevação da produção, maior eficiência e eficácia das organizações embasadas em um forte discurso de racionalidade. No cenário de expansão proporcionado pela Revolução Industrial despontaram também exigências da mão-de-obra, como direitos trabalhistas, melhores condições de trabalho e de remuneração, e a radicalização das lutas de classes. Nesse contexto desenvolveu-se a perspectiva clássica, cujos principais autores foram Taylor (1856 - 1915), Fayol (1856 - 1915) e Ford (1863 - 1947). Taylor (1999), conhecido como o pai da Administração, foi o responsável pela construção de uma abordagem técnica e prática do processo de trabalho. Sua obra aborda a defesa de um sistemático processo de produção com a finalidade de obter o máximo de produção, em torno desse discurso que tem como força motriz a divisão do trabalho são abordadas e conceituadas impressões em relação ao operário daquela época, visando ao final a criação de um discurso coerente aos objetivos empresariais.

Ford deu continuidade ao trabalho de Taylor e os principais elementos de destaque do seu estudo podem ser traduzidos em: produção de produtos padronizados, desenvolvimento da linha de montagem (o trabalho chega ao trabalhador), divisão e 
especialização do trabalho, ritmo de trabalho determinado (em função da velocidade da linha de montagem), baixos custos, controle externo e popularização dos automóveis (FORD, 1960).

Henri Fayol foi outro grande autor da abordagem clássica, tendo inaugurado a chamada "Escola de Chefes" com sua Teoria Clássica da Administração. Fayol deu enfoque à estrutura organizacional, como forma de se compreender a organização. Ele segmentou a empresa tanto em relações verticais com a divisão hierárquica em direção, gerência e operação, quanto em relações horizontais por meio dos departamentos. Com seus quatorze princípios, Fayol (1965) nutre uma visão racional da empresa, que deve se valer da previsão, organização, comando, coordenação e controle para alcançar seus objetivos.

A perspectiva clássica foi alvo de várias críticas, como por exemplo, as realizadas por Braverman (1987). O referido autor coloca em evidência o caráter alienante desenvolvido na perspectiva do trabalho científico, voltado exclusivamente para interesses econômicos e para acumulação de riqueza, e em contraponto, marcado principalmente pela desconsideração dos operários enquanto seres humanos utilizados e apropriados pelo capital apenas com interesse em sua força de trabalho.

O fator humano nas organizações passou a ser abordado na década de 20 pela Escola de Relações Humanas. Grande parte do conteúdo da Escola de Relações Humanas é fruto dos trabalhos de Elton Mayo, de seus associados e de seus alunos. Em suma, ao colocar sob análise fatores como o ambiente de trabalho, o humor do funcionário, a interrelação entre os aspectos externos e internos à organização e as consequências da lógica puramente econômica, característica da perspectiva clássica, Mayo (1959) permite a consideração da capacidade social do trabalhador e do comportamento do grupo como fator determinante para o estabelecimento de seu nível de competência em contraposição a teoria de tempos e movimentos que desconsiderava o indivíduo enquanto ser. A abordagem de Recursos Humanos é o elo que concilia os diversos interesses dos stakeholders (empresa, gerentes e funcionários) dentro do ambiente corporativo, tornandose, pois, uma das partes que integram a estratégia das organizações. Para dar sustentação a essa perspectiva entram em cena conceitos como motivação, liderança, participação e empoderamento.

Em oposição à perspectiva clássica e à abordagem de Recursos Humanos surge a teoria da Burocracia, cujo principal teórico é o sociólogo Max Weber. Para o autor, o conceito de racionalidade é o alicerce para a construção da modalidade de funcionamento dos sistemas sociais. Ressalta-se que racionalidade tem a ver com o estabelecimento da cadeia de meios e fins, ou seja, está relacionada com as decisões e "as alternativas consideradas meios adequados para atingir os fins desejados." (SIMON, 1965, p. 74). Desse modo, os meios devem ser avaliados e instituídos de maneira formal e impessoal, a fim de 
se alcançar a finalidade pretendida. Eis, então, um dos pilares que sustentam a Teoria da Burocracia.

A organização burocrática é marcada pela supremacia puramente técnica em detrimento de qualquer outra forma de organização (WEBER, 1946). Nessa perspectiva, algumas características marcam a superioridade técnica da administração burocrática tais como: precisão, velocidade, clareza, conhecimento dos arquivos, continuidade, discrição, subordinação rigorosa, redução do atrito, dos custos de material e pessoal (WEBER, 1946). "Trata-se do processo de deslocamento dos objetivos pelos quais um valor instrumental se converte em valor final." (MERTON, 1978, p.113). Esse deslocamento de objetivos produz rigidez, incapacidade de ajustes imediatos e o apego excessivo aos procedimentos formais, podendo interferir inclusive na consecução dos fins da organização.

Um caminho alternativo que concilia ao mesmo tempo os princípios da abordagem clássica e da escola das Relações Humanas e leva a uma perspectiva na qual as organizações devem estar atentas aos requisitos do ambiente, deu origem ao que ficou conhecido como Teoria Sistêmica. Expoentes dessa corrente, Katz e Kahn (1976), veem as organizações como sistemas abertos, caracterizadas por um dinamismo com a avaliação do processo na forma de feedbacks, uma espécie de monitoramento da estratégia, que retroalimenta o sistema de modo a possibilitar a sua perenidade dentro do ambiente evitando a entropia.

As ideias, conceitos, forças e limitações da perspectiva sistêmica forneceram os pilares da Teoria Contingencial, sendo Burns e Stalker os grandes expoentes desse pensamento. Eles distinguiram a estrutura mecanicista (na qual os papéis eram determinados por superiores que detinham o conhecimento organizacional) e a estrutura orgânica (em que os papéis organizacionais eram determinados de forma mais flexível, a partir de discussões entre as partes). Assim, a teoria da contingência forneceu em "um só golpe" uma síntese entre as perspectivas adotadas pela Escola Clássica da Administração e a Escola das Relações Humanas nas estruturas mecanicistas e orgânicas, respectivamente. Dessa forma, estruturas mecanicistas e orgânicas eram válidas em cada tipo de ambiente (DONALDSON, 1997).

Seguindo a evolução das teorias organizacionais, no início da década de 70 surge o Neoinstitucionalismo. Segundo Meyer e Rowan (1991), a principal característica dessa institucionalização é a criação de mitos, visto que o cotidiano revela a face real das organizações que são caracterizadas por mesclar diversas realidades e racionalidades, descolando-se assim do formalismo empregado. Tamanha formalidade e racionalidade utilizadas em um ambiente acabam por criar um isomorfismo. Esse conceito característico da teoria neoinstitucional diz respeito à adequação da sociedade às instituições e pode ser 
traduzido como o condicionamento e reprodução de determinadas práticas legitimadas pela sociedade. Sendo assim, Meyer e Rowan (1991), evidenciam a construção de um isomorfismo organizacional e afirmam que na medida em que os mitos se desenvolvem, forçam as organizações a acomodá-los em suas estruturas.

Conforme visto até esse ponto, todas as teorias organizacionais se voltaram para os interesses econômicos, embasados por uma concepção positivista que buscava, a qualquer custo, o progresso e a elevação da produtividade. A Teoria Crítica, conforme Alvesson e Deetz (1999) afirmam, surge como resposta alternativa ao modernismo marcado pela exacerbada racionalidade e busca pelo controle das organizações e consequentemente dos indivíduos. O desenvolvimento tardio desse ponto de vista crítico revela o caráter dogmático construído pelas perspectivas anteriores, porém com o enfraquecimento das duas principais correntes ideológicas daquela época - Positivismo e Marxismo - criou-se campo fértil para as indagações provenientes da teoria crítica e também de sua vertente mais radical, as concepções pós-modernistas.

Esse pensamento se sustenta em pressupostos diferentes da lógica vigente até o momento e seu embasamento teórico é proveniente das teorias originadas na escola de Frankfurt e pelas concepções de filósofos como Focault, Deleuze e Derrida, criando assim uma concepção que visa a emancipação do ser humano e o questionamento dos modelos de condicionamento e exploração das minorias. Suas críticas são direcionadas principalmente para o modo de dominação da classe detentora de poder em relação aos diversos grupos que compõem a sociedade, principalmente as minorias desfavorecidas, como negros, pobres e mulheres. Seus questionamentos se voltam para dimensões a respeito do processo de naturalização da exploração, da primazia da racionalidade técnica, da consideração dos interesses da elite como sendo interesses gerais e também em relação ao processo hegemônico que se desenvolve na sociedade e buscam, em suma, a emancipação do ser humano (GUERREIRO RAMOS, 1981).

A partir dos conceitos abordados pela Teoria Crítica, surgem outras teorias orientadas por ideais reformistas, como forma de adequar as organizações às questões sociais emergentes. Dentre os estudos críticos, além dos autores já mencionados, há aqueles que deram ênfase às questões relativas às minorias sociais, fato que apontado como promotor de uma reconstrução da teoria ética. Esses estudos denunciaram processos preconceituosos e racistas e apontaram a importância de se definir a quem pertencem os interesses que devem ser tratados, revelando a postura política das teorias já existentes, tidas como neutras (CHRISTIANS, 2006). Dentre esses estudos, passa-se a se discutir no próximo tópico a Gestão da Diversidade, tecnologia gerencial oriunda do debate sobre o racismo nas organizações. 


\subsection{Gestão da diversidade: promoção das diferenças ou controle?}

A crescente precarização da qualidade de vida motivou a reação de diversos grupos sociais a lutarem por mudanças. Em meados do século XIX, a Europa assistiu movimentos LGBTIQ (Lésbicas, Gays, Bissexuais, Travestis, Intersex e Queer) a lutarem contra a criminalização de pessoas e relações sexuais dissidentes. Em 1960, nos Estados Unidos, diversos grupos sociais começaram a denunciar injustiças sociais (ALVES, GALEÃO-SILVA, 2004). As Panteras Negras, por exemplo, deram visibilidade ao genocídio e à subcondição de vida imposta as pessoas negras naquele país.

Historicamente o mito da democracia racial (FREYRE, 2002; HOLANDA, 1995) persuade as pessoas sobre a inexistência de racismo no Brasil, algo possível por meio do processo de miscigenação ocorrido no país. Essa concepção está alinhada ao ideal do consenso, ao negar o conflito racial. Porém, as diferenças sociais atreladas ao fato de que as classes sociais podem ser caracterizadas por critérios econômicos e de cor, demonstram que esse mito não se sustenta. Paixão e Carvano (2008) organizaram o Relatório Anual das Desigualdades Raciais no Brasil, no trabalho foram abordadas questões relativas à demografia, mortalidade, acesso à educação, mercado de trabalho, condições de vida e acesso ao poder institucional. É possível perceber que a pobreza foi historicamente construída (BRANT, 2011) por diversos fatores, porém, a exploração do trabalho escravo no país aliada ao abandono dos escravos a própria sorte quando o sistema escravagista já não se mostrava conveniente contribuíram em grande medida para esse quadro.

De acordo com Paixão e Carvano (2008), a mortalidade infantil é considerada um fator chave para se compreender o modo de vida e o acesso a serviços básicos como saúde e educação de grupos sociais. No Brasil, em 2006 observou-se que 24,4\% das crianças que morrem até o primeiro ano de vida são filhos de mães negras ou pardas, enquanto que de mulheres brancas são 19,4\%. Em média, pessoas brancas vivem 3,2 anos a mais que pessoas negras (PAIXÃO, CARVANO, 2008, p. 38-40).

Outro fator importante para entender a situação de pessoas negras é a violência a que estão expostas. Em 2005 observou-se que dos 54,682 mil assassinatos ocorridos no país, 27,483 mil eram pessoas negras ou pardas, o que representa 56,36\% do total. Quando se observa o período entre os anos de 1999 a 2005, chama atenção a tendência de crescimento da quantidade de assassinatos de pessoas negras ou pardas (Id. Ibid, p. 50). Ainda de acordo com o estudo, dos 14,4 milhões de analfabetos no ano de 2006, 67,4\% eram negros ou pardos ( $/ d$. Ibid, p. 67). No mesmo ano, observou-se que dos 4.027.2710 de pessoas que acessaram o ensino superior, apenas 1757.336 eram negros ou pardos ( $/ d$. Ibid, p. 80). No que se refere ao mercado de trabalho, negros possuem menor índice de 
empregos com carteira assinada e a grande maioria trabalha em atividades básicas, como trabalhador com ou sem carteira assinada, serviço doméstico ou em alguma atividade autônoma, esses sem ensino superior. Ao se observar a população branca, percebe-se que são a maioria nos cargos públicos ou militares, são a maioria com empregos de carteira assinada e os que são autônomos, possuem o ensino superior. Esse grupo também é majoritário como empregador (ld. Ibid, p. 94).

Com relação aos cargos executivos em 2005 conclui-se que 94,4\% pertenciam a pessoas brancas, $0,5 \%$ a negros, 2,9\% a pardos e 2,2\% a amarelos. Pessoas brancas representam 89,0\% dos ocupantes dos cargos de gerência, enquanto negros ou pardos somam 9,0\%. Quando observados o quadro funcional, $68,7 \%$ são brancos contra $26,4 \%$ de negros e pardos (Id. Ibid, p. 96). Quanto mais alto o cargo se encontra na pirâmide hierárquica organizacional, menor a chance de ser ocupada por alguém negro ou pardo. $A$ avaliação do rendimento domiciliar no ano de 2006 evidencia que 77,9\% das pessoas localizadas no decil (rendimento médio dividido em dez faixas de renda, em ordem crescente) mais rico do país são brancas. No extremo oposto, $72,9 \%$ das pessoas com a menor renda são negras ou pardas (Id. Ibid, p. 116). Por derradeiro, há a condição da posse da terra como possibilidade de parceiro, arrendatário, posseiro, cessionário, proprietário ou outras condições. Dentre as pessoas brancas, $75,5 \%$ são proprietárias, enquanto apenas $59,9 \%$ dos negros ou pardos são proprietários (Id. Ibid, p. 139). Como já mencionado, a posse da terra é uma questão histórica, já que as pessoas que viviam em condição de escravidão, quando libertas, foram abandonadas sem qualquer benefício seja dos antigos senhores ou do governo.

Diante desse quadro, o apelo à intervenção estatal foi visto como necessária como garantia à promoção da equidade, entendida como igualdade de condições no acesso às oportunidades. Para tanto, as ações devem levar em consideração as necessidades de cada grupo social, visto que o tratamento igualitário dos diferentes conserva ou aprofunda as desigualdades existentes. Ao observarem a dinâmica das organizações, Saraiva e Irigary (2009) afirmam que tratar os diferentes de forma equitativa "não é desconsiderando as assimetrias que se incluem segmentos discriminados nas organizações, mas considerando que as diferenças são um ganho ao refletirem a heterogeneidade da sociedade." Essa concepção é tida no campo social como forma de promover justiça social.

Assim surge o Diversity Management (COX, 1991) ou Gestão da Diversidade (FLEURY, 2000) no Brasil no início dos anos 2000. Essa tecnologia gerencial busca convencer as empresas a promover a diversidade em seus respectivos quadros funcionais. A diversidade foi reduzida a um selo, capaz de agregar valor a imagem da organização ou uma vantagem competitiva, uma vez que reflete práticas socialmente responsáveis 
(KUABARA; SACHUK, 2011). Além disso, há a oportunidade de acessar certos mercados até então não considerados.

Jaime (2016) realizou um trabalho etnográfico com executivos negros a fim de entender as estratégias pessoais adotadas para conseguir ascender profissionalmente em um contexto adverso. Nos relatos, é possível perceber que as empresas, todas do setor bancário, adotaram formas de promoção da diversidade, mas na perspectiva gerencial. Assim, gerir a diversidade, poderia resultar em ganhos financeiros. As empresas usaram o selo da diversidade, visando o mercado de pessoas negras, que havia aumentado seu poder de compra em grande medida nos últimos anos. A maior parte dos relatos tem início com a negação de alguma experiência racista, contudo, as várias ocorrências surgem ao longo das entrevistas. Todos os executivos disseram que quando expostos a situações racistas, ignoraram, já que evidenciar o conflito não era algo desejado. As mulheres relataram diversas situações envolvendo violências físicas inclusive, além de, em alguns casos, a impossibilidade em ocupar certos cargos ou em caso da ocupação, sujeitando-se a salários expressivamente menores pagos para outros funcionários de igual posição.

A adesão de práticas e técnicas de forma desproblematizada ou despolitizada (ALVES, GALEÃO-SILVA, 2004) pode resultar em inserção profissional, mas implica na manutenção das lógicas preconceituosa, racista, homofóbica e tantas outras, presentes na sociedade e consequentemente nas organizações. Organizações não resolvem questões sociais, elas as reproduzem. Cabe a nós, enquanto sociedade, a superação de nossas questões, reconhecendo que a consciência delas é o primeiro e o mais necessário dos passos.

Garcia e Bronzo (2000) argumentam que os processos científicos não podem ser tomados como uma atividade desinteressada e neutra. As teorias refletem interesses e crenças dos diversos autores, coerentes com as bases epistemológicas e políticas, responsáveis pela natureza do conhecimento e sua justificação. Ao analisar a evolução das teorias da Administração, é possível perceber que o argumento do desenvolvimento as perpassa e sugere que as novas práticas são capazes de proporcionar avanços às organizações e com isso, a todos os que estão envolvidos com as mesmas (BITENCOURT, 2009). No campo organizacional, a tecnologia e o discurso científico são mecanismos oriundos do desenvolvimento e que combinados, foram responsáveis pelo surgimento de novos modos de saber e fazer. 


\subsection{Teorias da Administração: desenvolvimento para quem?}

Muitas concepções de ideal no que alude a sociedade já pautaram o comportamento das pessoas, mas nenhum discurso foi tão forte quanto o do desenvolvimento, que marcou o início do século XX e perdura até os dias atuais. Mas o que seria esse desenvolvimento? Uma prática que sofre desenvolvimento caminha em que sentido? Por que desenvolver-se se tornou algo tão importante? O termo é polissêmico (GÓMEZ, 2002) e pode fazer referência tanto a algo amplo em constante desenvolvimento, quanto o contrário, algo tomado por seu detalhe, pormenorizado. É possível notar que o termo desenvolvimento é ambíguo já em seu entendimento, pois, como pode algo servir para explicar um ideal de tamanho se ao mesmo tempo se refere a extremos? Outro caminho para a compreensão do termo é estudar como ele é aplicado nas diversas esferas sociais.

No mundo corporativo, desenvolvimento também guarda relação sinônima com tamanho. Para a organização desenvolvida, melhor é o maior: vendas, número de clientes, empregados e o próprio tamanho da empresa. Santos et al. (2002) fizeram um estudo e encontraram algumas dimensões relacionadas a esse tema, dentre as quais sobressaem a Política, a Economia e a Social. O desenvolvimento econômico se refere a um conjunto de práticas, constituídas de metodologia e teorias próprias, que proporcionaram a sociedade industrial e urbana o acúmulo de capital. O expoente dessa concepção é Smith (1996) que defende as pessoas enquanto seres movidos pelo desejo do lucro, como forma de suprir suas necessidades individuais e com isso, alimentariam toda a cadeia ao produzirem um excedente que beneficiaria a todos.

Já a noção de desenvolvimento no contexto político surge nos Estados Unidos no período Pós Segunda Guerra Mundial. Na época, modernidade, crescimento e progresso foram considerados elementos presentes em sociedades desenvolvidas, e que essas proporcionariam às nações subdesenvolvidas o alcance dessas características por meio da ciência e distribuição justa e democrática de recursos (TRUMAN, 1949).

A dimensão social do desenvolvimento é entendida de acordo com os parâmetros definidos pela Organização das Nações Unidas (ONU), responsável pela formulação do Índice de Desenvolvimento Humano (IDH), que mede o progresso ao acesso à renda, saúde e educação por meio de uma metodologia que permite a relação entre essas esferas. Com base na métrica utilizada, foi criado um ranking global (PNDU, 2017). O campo organizacional utiliza em larga escala do termo desenvolvimento. Lobos (1975) entende que a Teoria de Desenvolvimento Organizacional se refere a um conjunto de práticas planejadas que visam a mudança, alterando padrões comportamentais tradicionais por novos. 
Como já evidenciado, Taylor inaugurou as práticas voltadas para ganhos produtivos. Desde então, os diversos trabalhos ganharam notoriedade por promover o aumento, seja produtivo ou de qualquer outra ordem, resultando em maiores lucros. Dessa forma, tudo que confere aumento, recebe o selo do desenvolvimento, de modo que implicitamente, entendase que a prática que é sinônimo de progresso, modernidade e avanço (GÓMES, 2002). A interpretação de desenvolvimento como aumento ocorreu de forma coerente com a lógica econômica vigente. Todos os demais elementos associados ao termo são ignorados para justificar a crescente e constante preocupação com a expansão. Percebe-se que o foco nas métricas das empresas, marginalizou por muito tempo o fator essencial para a existência das mesmas: o ser humano. Mesmo na década de 20 quando a Escola das Relações Humanas apontava para a centralidade das pessoas nas organizações, notava-se o interesse por trás do discurso que se voltava para a administração dos fatores humanos, mas que apresentava como real objetivo o aumento dos resultados empresariais.

A análise das teorias desenvolvidas por Taylor, Ford e Fayol revelam valores positivistas com a divisão do trabalho e a busca da eficiência, que resultam na especialização extrema. Essa especialização hierarquiza as relações proporcionando o controle das mesmas. Os autores estabelecem o modus operandi do gerente. Pregam a harmonia na empresa e apresentam uma visão muito restrita do trabalhador. A divisão entre o saber e o fazer impacta fortemente na qualidade de vida dos trabalhadores. Porém, a dimensão psicológica inerente às organizações é ignorada pelos autores. Braverman explora as relações de trabalho, demonstrando o seu processo de fragilização.

Atualmente, o que se percebe é que os estudos de Taylor marginalizam elementos importantes presentes nas relações de trabalho, dando importância excessiva ao processo. Fayol ao valorizar a estrutura, também marginalizou a discussão sobre as relações de trabalho. A forma usada pelos dois autores para resolver essa dimensão organizacional se dá por meio do constante repúdio ao conflito em suas obras. Braverman não define a classe trabalhadora por entender que isto implica reducionismo e adverte que não se pode tratar a questão em termos estáticos. Para ele, o trabalho humano é marcado por complexas interações entre os meios de produção e as pessoas. O capitalismo mercantil era caracterizado por oficinas pequenas e não apresentava uma produção que satisfizesse os interesses dominantes. A gerência surge como alternativa para impor ritmo e controlar a conduta dos trabalhadores. Se por um lado a divisão social do trabalho fragmenta a sociedade, por outro a divisão do trabalho fragmenta o homem. Dessa forma, a busca pela especialização resulta em alienação. As empresas negam os diversos conflitos sociais, e no contexto brasileiro a questão racial é forte, como forma de obtenção do consenso nas organizações. 
O enfoque nos processos e na estrutura demonstram limites claros, e Mayo (1959) inaugura a reflexão sobre os fatores que influenciam o comportamento humano no interior das organizações. É errônea a conclusão de que Mayo e seus colaboradores negaram que o incentivo econômico não motiva os trabalhadores. O que disseram é que esta não é a única forma. Superar a ideia de homus economicus foi importante, pois marcou a transição da visão de indivíduo isolado enquanto trabalhador, para alguém integrado a um grupo. Hoje, os estudos sobre motivação se valem de diversos fatores que podem ou não ser monetários. Para tanto, Maslow (1970) é outro autor muito utilizado, tendo em vista que evidenciou as necessidades humanas. Contudo, a reflexão sobre os aspectos humanos da organização promovida por esses autores foi condicionada os fatores capazes de promover a expansão do capital, em detrimento das condições sociais dos trabalhadores. A Escola das Relações Humanas desenvolveu teorias de cunho funcionalista e novamente, ignorou as variáveis humanas que não diziam respeito à elite dominante.

Posterior a essa concepção, a Burocracia surge como alternativa às lacunas observadas nas teorias já realizadas. Apesar da conotação negativa relacionada à Burocracia atribuída às suas disfunções, é difícil conceber instituições públicas ou privadas sem uso de normas e técnicas para organizá-las, o que marca um paradoxo. Questionar a própria conduta é algo desestimulado, pois deturpa uma lógica que privilegia a norma, o padrão, a obediência a um modus operandi previamente definido por instâncias privilegiadas do saber técnico necessário para concepção do processo de trabalho. A Burocracia adquiriu o status de um "mal necessário", pois remete à organização do Estado, este concebido mediante a necessidade de garantir às pessoas, acesso mínimo a serviços básicos que possibilitem a manutenção da força de trabalho, uma vez que o capitalismo enquanto sistema social por si só não se sustenta e já que fabrica desigualdades, em algum nível inviabiliza a própria relação de trabalho. Dessa forma, a necessidade de haver um Estado e da Burocracia como forma de sua organização, são consequências diretas da marginalização das questões sociais pelas empresas.

Já as teorias contingenciais surgiram do embate entre a Escola Clássica e Escola de Recursos Humanos. Essa abordagem, vista por muitos não como uma teoria consolidada, e sim como ideias com esta preocupação, tem como objeto central a organização, não considerando o indivíduo nas análises. Observa-se uma inadequação conceitual, uma vez que essa corrente se apropria de conceitos da Biologia e os aplica no contexto das organizações. O darwinismo social presente na obra de Morgan é uma forma de evocar justificativas escusas para explicar que a organização reflete a lei natural como forma de legitimação (ignora a autonomia do ser humano influenciando as escolhas).

Sequencialmente, o neoinstitucionalismo marcado pela preocupação dos mecanismos legitimadores das práticas organizacionais. A lógica de formalização e 
racionalidade oriundas do ideal positivista e funcionalista faz com que haja um descolamento entre o real e o ideal observado no campo organização. A preocupação passa a ser sobre como a empresa é vista, em detrimento daquilo que ela realmente é. Guerreiro Ramos (1981), ao observar a evolução das Teorias da Administração demonstra que esse desenvolvimento ocorreu em direção aos interesses de determinados grupos dominantes.

Os estudos críticos concederam evidência ao preconceito e racismo nas organizações, demonstrando processos de segregação e marginalização até então não problematizados. Essas críticas foram apropriadas no contexto organizacional numa perspectiva reformista, dando origem a Gestão da Diversidade (COX, 1991). Porém, verificase que a apropriação das críticas se dá sob o apelo do desenvolvimento, mas ocorre de forma comprometida somente na perspectiva da empresa, de modo que as questões que deram origem às políticas específicas permaneçam sem a devida problematização, como é possível perceber no estudo de Jaime (2016) e alertado no texto de Alves e Galeão-Silva (2004).

\section{Conclusão}

Observa-se que as teorias da Administração evoluíram problematizando a velocidade da produção, o tamanho da empresa e a quantidade de recursos. Todos esses fatores refletem aspectos que podem ser mensurados, refletindo dessa forma o ideal científico de racionalidade e instrumentalidade da gestão. Para Taylor, Fayol e Ford, o planejamento e controle organizacional poderiam ser obtidos por meio do equilíbrio entre os objetivos organizacionais e pessoais. Assim, o consenso no interior das empresas foi tomado como ideal, como ressaltado por Garcia e Bronzo (2000).

É possível inferir que a busca pelo consenso, marginalizou diversos aspectos sociais complexos, também presentes nas empresas como é o caso da questão étnico racial e do racismo no contexto brasileiro. Gómez (2002) critica o conceito do desenvolvimento por entender que um dos sentidos atribuídos ao termo é o consenso, esse que de forma recorrente foi problematizado pelas teorias da Administração, obtido por meio da ausência ou minimização do conflito. A busca desse ideal prega a harmonização de interesses mesmo sendo antagônicos, tais como os conflitos de classe e raça. Essa harmonia seria fruto do processo de construção envolvendo os trabalhadores, que ao se verem incluídos nas decisões, estariam garantindo que seus interesses fossem contemplados. Na prática, a participação nas decisões não confere nenhum poder decisório aos trabalhadores, a flexibilização das possibilidades ocorre sempre de modo que os interesses das classes 
dominantes sejam preservados, fato que demonstra que tais práticas são mais mecanismos de controle do que meios para construção coletiva.

As teorias da Administração são parte de um conjunto que, sob o argumento do desenvolvimento, de forma efetiva pouco tem oferecido de avanços concretos no que se refere às questões sociais como presente no trabalho de Rosa (2014). Sob esse aspecto, Aktouf (1996) entende que as Teorias da Administração são doutrinas que impõem aos empregados um comportamento submisso. O trabalhador ideal é aquele com baixa resistência e alta obediência aos padrões pré-estabelecidos, o que denota o nível de eficácia da empresa. Para tanto, as teorias se sustentam em pilares como disciplina, ordem, hierarquia, separação de papéis de planejamento e execução.

A coisificação das pessoas nos processos produtivos evidenciada por Aktouf limita a capacidade das mesmas e é algo que prejudica as próprias organizações. Somado a esse aspecto, o desenvolvimento e evolução das Teorias da Administração ocorreram, na maior parte do tempo, de forma alheia às questões sociais, inclusive as que acometem minorias, reproduzindo os processos presentes na sociedade. A falta de problematização pode ser entendida como a negação dos conflitos como forma de alcance da harmonia no interior das organizações.

De acordo com reflexão teórica impulsionada pelo questionamento de como as Teorias da Administração abordam questões de ordem social sob a ótica étnico racial considerou-se que até década de 80 as Teorias da Administração tiveram sua evolução pautada unicamente pelos fatores ligados diretamente ao objetivos organizacionais, orientados pelos princípios da eficiência e eficácia. Essa situação demonstra que os problemas passíveis de tratamento teórico no campo da Administração se resumem aos que pudessem ser observados nos processos produtivos, fato que tornou alheio qualquer outra questão e aí estão as sociais, de análise científica nessa área do saber. Com a ascensão e repercussão de estudos críticos, questões sociais passaram a ser debatidas no ambiente organizacional e tecnologias gerenciais foram criadas visando reformar os processos produtivos como é o caso da Gestão da Diversidade, essa que deve ser compreendida dentro do quadro em que emerge: um campo teórico comprometido com determinado meio de produção e interesses. Sendo a Gestão da Diversidade composta de práticas e técnicas voltadas à promoção das diferenças nas organizações, sua criação e adoção não é suficiente para promover a profundidade demandada por questões sociais complexas como é caso do racismo proveniente da discriminação étnico racial, o sexismo, a homofobia e outros, pois tratam-se de processos desenvolvidos sob o manto da negação de sua existência por centenas de anos no contexto brasileiro. Assim, o tratamento teórico de questões sociais, para esquivar-se do debate superficial e modismos, deve levar em consideração a complexidade social de onde as questões emergem. 


\section{REFERÊNCIAS}

AKTOUF, Omar. A administração entre a tradição e a renovação. São Paulo, Atlas, 1996. ALVES, M. A. GALEÃO-SILVA, L. G. A crítica da gestão da diversidade nas organizações. RAE-Revista de Administração de Empresas, 44, 2004.

ALVESSON, M.; DEETZ, S. Teoria Crítica e abordagens pós modernas para estudos organizacionais. In: CLEGG, S. et al. (org) Handbook de estudos organizacionais: volume 1. São Paulo: Atlas, 1999.

BERNARDINO J. Ação afirmativa e a Rediscussão do mito da democracia racial no Brasil. Estudos Afro-Asiáticos, Rio de Janeiro, ano 24, n.2, p. 247-273, 2002.

BITENCOURT, Claudia. Gestão Contemporânea de Pessoas: Novas Práticas, Conceitos Tradicionais. Bookman Editora, 2009.

BRANT, Nathália Lopes Caldeira. Política social e capitalismo: a política de educação na dinâmica da sociedade capitalista. Caminhos da Educação, v. 3, n. 2, 2011.

BRAVERMAN, H. Trabalho e capital monopolista - a degradação do trabalho no século XX. Rio de Janeiro: Guanabara, 1987.

CARIBÉ, DANIEL ANDRADE. Ciência ou ideologia? A constituição do campo da administração política. Revista Brasileira de Administração Política, v. 1, n. 1, p. 31, 2008.

CHRISTIANS, C. G. A ética e a política na pesquisa qualitativa. In: DENZIN, N. LINCOLN, Y. $O$ planejamento da pesquisa qualitativa: Teorias e abordagens. Porto Alegre: Artmed, 2006.

COX, T. Cultural diversity in organizations: theory, research and practice. San Francisco : Berrett-Koehler Publishers, 1991.

DOMINGUES P. Movimento negro brasileiro: história, tendências e dilemas contemporâneos. Dimensões, Vitória, v. 21, p.101-124, 2008.

DONALDSON, L. Teoria da contingência estrutural. In: CLEGG, Stewart; HARDY, Cynthia; NORD, Walter R. Handbook de estudos organizacionais. São Paulo: Atlas, Vol 1, 1997. FAYOL, Henri. Administração industrial e geral: previsão, organização, comando, coordenação, controle. Atlas, 1965.

FLEURY, Maria Tereza Leme. Gerenciando a diversidade cultural: experiências de empresas brasileiras. Revista de Administração de Empresas, v. 40, n. 3, p. 18-25, 2000. FORD, H. Os princípios da prosperidade. Rio de Janeiro: Brand, 1960. 
GARCIA, Fernando Coutinho; BRONZO, Marcelo. As bases epistemológicas do pensamento administrativo convencional e a crítica à teoria das organizações. Encontro de Estudos Organizacionais da Associação Nacional de Pós-Graduação e Pesquisa em Administração, v. 1, 2000.

GOMEZ, Jorge Ramon Montenegro. Crítica ao conceito de desenvolvimento. Revista Pegada, v. 3, n. 1, 2002.

GUERREIRO RAMOS, A. A nova ciência das organizações: uma reconceituação da riqueza das nações. Rio de janeiro: FGV, 1981.

FREYRE, G. Casa-grande \& senzala. Rio de Janeiro: Record, 2002.

HOLANDA, S. B. Raízes do Brasil. São Paulo: Companhia das Letras, 1995.

JAIME, P. Executivos Negros: racismo e diversidade no mundo empresarial. São Paulo: Ed. da Universidade de São Paulo, 2016.

KATZ, Daniel; KAHN, Robert Lester. Psicologia social das organizações. 2. ed. São Paulo: Atlas, 1976.

KUABARA, P. S. S. SACHUK, M. I. Apontamentos Iniciais Sobre a Gestão da Diversidade: Dilemas e Significados. Revista Cesumar Ciências Humanas e Sociais Aplicadas, 2011. LAVALLE, Adrián Gurza; CASTELLO, Graziela; BICHIR, Renata Mirandola. Protagonistas na sociedade civil: redes e centralidades de organizações civis em São Paulo. DadosRevista de Ciências Sociais, v. 50, n. 3, 2007.

LIMA, M. Desigualdade raciais e políticas públicas: ações afirmativas no governo Lula. Novos Estudos, São Paulo, n. 87, p. 77-95, 2010.

LOBOS, Julio. Desenvolvimento organizacional: teoria e aplicações. Rev. Adm. Empresas, v.15, n.3, São Paulo,1975.

MASLOW, Abraham Harold et al. Motivação e personalidade . Nova York: Harper \& Row, 1970.

MAYO, E. Problemas humanos de una civilización industrial. Buenos Aires: Galeta, 1959.

MERTON, Robert King. Burocrática e personalidade. In: Edmundo Campos (org). Sociologia da Burocracia, 4. ed. Rio de Janeiro: Zahar, 1978.

MEYER, J. W.; ROWAN, B. Institutionalized organizations: formal struture as myth and ceremony. In: POWELL, W. W.; DiMAGGIO, P. J.(Ed.). The new institucionalism in organizational analysis. Chicago: The University of Chicago Press, 1991.

PAIXÃO, Marcelo. CARVANO, Luiz M. (orgs). Relatório Anual das Desigualdades Raciais no Brasil (2007-2008). Rio de Janeiro, 2008.

PNDU. Desenvolvimento Humano e IDH. Disponível em: < http://www.br. undp.org/content/brazil/pt/home/idh0.html >. Acesso em 10 jul. 2017. 
ROSA, Alexandre Reis. Relações raciais e estudos organizacionais no Brasil: dimensões esquecidas de um debate que (ainda) não foi feito. Anais, Encontro Nacional da Associação Nacional de Pós-Graduação e Pesquisa em Administração, 2012.

SANTOS, Elinaldo Leal; BRAGA,Vitor; SANTOS, Reginaldo Souza; BRAGA, Alexandra Maria da Silva. Desenvolvimento: um conceito em construção. DRd-Desenvolvimento Regional em debate, v. 2, n. 1, p. 44-61, 2012.

SARAIVA, L. A. S., IRIGARAY, H. A. D. R. Políticas de diversidade nas organizações: uma questão de discurso? RAE-Revista de Administração de Empresas, 2009.

SILVA, Leandro Vedovato da; ANHOLON, Rosley; SILVA, Dirceu da; QUELHAS, Osvaldo Luiz Gonçalves. Análise dos Principais Fatores Observados em Mudanças Organizacionais: Uma Revisão da Literatura. In: Simpósio Internacional de Gestão de Projetos, Inovação e Sustentabilidade, Anais, VI SINGEP, São Paulo, dez. 2017.

SIMON, Herbert Alexander; FUNDAÇÃO GETÚLIO VARGAS. Comportamento administrativo: estudo dos processos decisórios nas organizações administrativas. Rio de Janeiro: Fundação Getúlio Vargas, 1965.

SMITH, Adam. A Riqueza das Nações. Trad. Luiz João Baraúna, São Paulo: Abril Cultural, 1a ed., vol. 1, 1996.

TAYLOR, F. W. Princípios da Administração Científica. São Paulo: Atlas, 8ª ed. 1999.

TRUMAN, Harry S. Inaugural Address. 20 jan. 1949. Disponível em < https://www.trumanlibrary.org/whistlestop/50yr_archive/inagural20jan1949.htm>. Acesso em 10 dez. 2017.

WEBER, Max. Ensaios de sociologia. Rio de Janeiro: Zahar, 1946. 